\title{
LÍNGUAS SILENCIADAS, NENHUMA A MAIS!
}

Silenced languages, not a single one more!

\author{
Ana Vilacy GALUCIO \\ Museu Paraense Emílio Goeldi \\ avilacy@museu-goeldi.br \\ https://orcid.org/0000-0003-0168-1904
}

\section{Ameko pebo piro}

\section{(A onça que tinha asas)}

\section{Narradora Vicência Sakyrabiar}

Pu ke sogap setoa imãyã opomãyã.

Kaat kwaksoa õt kẽrõ ẽrẽt ke sogap setoa ke kwaap.

Oapitkwaraapõõt nẽngãrẽp te pe amẽko keat kaat iko keat ekoreri'ẽp sete.

Amẽko pebo piro kaat.

Kẽrã yẽẽp te pagop taip keat ekot esayẽ.

Kwep kwep kwep kẽrã kerep yẽpe pe ãtka eba kikwara kubek.

Arẽp kot serek peyẽ ikotkup uut poret ika sekoa.

Pot pot pot te saako sau sabababa keareri. Ãtka yẽẽt kẽrã, kẽrã te ikip kuy esayẽ ekorese.

Ãtka yẽẽt kẽrã sete.

Setitnã yẽẽt kẽrã yẽ.

Poret kẽrã te imãkorope pok kẽrã ekot pibõ'ẽp pomãyãpnã emõ ikoabõ.
Arẽp kẽrã sete soa pase kekwaarõ kẽrã yẽẽt te potẽẽt poret.

Poret peporok suruk ẽ'esẽp ekwea nẽãrã ipomãyã pe seteyat top teyat si.

Kete ãtkaat te arop amẽko pebo piro iko sete.

Oikwaksop sĩ̃t opooriat taabiat õpikwak. Arẽp kẽrã te itobiat aose sara koopit.

Eke'ẽp te sete ikaeseka puruk puruk keareri.

Aa' potẽẽt pisa nããt top aose ekap eke eteet i'ot sarakwamõyat kuyõ.

Poret sepirigara sekoa te kwe nẽnõat suuyuy seut ekap eteet.

Ãtkaa sese kenõãt kẽrã.

Poret ipitka kẽrã pereret pay pereret pay.

Erõmõ ka poret sete pok.

Ke itoa poret kuabõ pei.

Satoapnã pe siko.

Ke te kaap te oikwaksop ãtkaa.

Mãy kaap sĩit oikwaksop.

Nẽngãrẽp eba te otarõ setisa pokat. 


\section{revista $\boldsymbol{X}$}

Sete ke te kaap tẽẽt eba oikwaksop.

Ikwaksoa õt kipooriat taabiat mãyã seisa eyat obasoyat. Peregerõp se.

$* * * * * * * * * * * * * * * * *$

Meu tio ficava deitado sossegado. Assim que ele ficava contando as coisas. Contava pra mim. Você pensa que você já escutou essas coisas? Eu não me esqueci também que a onça que tem asas comeu o rapaz, dentro da tocaia ${ }^{1}$.

Dois irmãos foram caçar à noite. Foi quando apareceu essa onça que tinha asas. Ali mesmo, quando o rapaz estava sentado lá em cima na tocaia. A onça subiu, subiu, chegou, entrou, e estava lá o rapaz. Ela pegou e não teve jeito do rapaz escapar. Ela cortou o pescoço dele e chupou, depois ficou comendo ele todinho lá em cima.

Os ossos dele foram caindo e o sangue derramando igual chuva. O irmão do rapaz, que estava no chão, na tocaia embaixo, pensou:

- O quê ele está fazendo? O que será que ele está fazendo?

Nisso, esse irmão que estava embaixo viu cair o sangue e falou primeiro assim:

- Mas o que será que ele está fazendo,

\footnotetext{
${ }^{1}$ Um abrigo temporário construído tanto no alto das árvores, quanto na base, onde o caçador faz tocaia, esperando a caça.
}

será que ele está mijando?

Então a costela do que estava em cima caiu dentro da tocaia, parece que veio só pra avisar. Caiu assim bem perto do irmão dele.

Ele percebeu bem e pensou:

- Ih! já aconteceu isso. Que tragédia! Ele, assim que percebeu o que estava acontecendo, já saiu logo. Ele saiu da tocaia e correu, foi avisar o pai e a mãe deles.

Meu tio contou assim a história que a onça que tem asas comeu gente. Eu escutei um pouquinho a história da tradição dos meus pais.

Quando o rapazinho contou o que estava acontecendo, os pais já se alvoroçaram, já reuniram bastante gente.

- Ainda está lá comendo, quebrando o osso, lá de cima.

O rapaz contava. O pessoal, então, já começou a se preparar, estavam todos andando alvoroçados, no chão perto da tocaia, falando uns pros outros: - Não deixa escapar, não vão só ferir.

Nisso ele vinha descendo, o bicho enorme, vinha escorregando que a barriga estava grande. Veio escorregando até certa altura, não deixaram ele chegar mais baixo e começaram a atirar com flecha, pereret pay pereret pay, era o 
barulho das flechas!

Quando começaram a flechar, ele corria pra cá, corria pra lá, daí caiu, pok! Quando estava no chão, pegaram a espada de pupunha e com aquilo bateram que esbagaçou, pey! Outro veio e, pot pot pot, bateu na cabeça assim, hiii! Aí morreu. Depois ficaram catando o osso do rapaz para levar para enterrar.

Fizeram isso pra vingar a morte do rapaz que o bicho comeu. Diz que é assim, que eu escutei assim. Assim que eu escutei um pouquinho que os outros contavam. É igual essa que se queimou com fogo. É desse jeito assim que eu escutei. $\mathrm{Eu}$ escutei quando os meus pais contavam, que são os avós de vocês. Não faz muito tempo essas coisas. Assim que eu escutava, não esqueço não. Só é assim, não é muito longa (essa história).

Ameko pebo piro ou "A onça que tinha asas" é uma das narrativas que compõem a cosmologia fantástica do povo Sakurabiat. Essa história me foi contada, durante projeto de documentação da língua dos Sakurabiat, por uma das minhas tias-avós Sakurabiat, a Sra. Vicência Sakyrabiar. Desde a primeira vez que adentrei em sua aldeia, em 1994, fui recebida por ela e pelas outras três anciãs do povo Sakurabiat como uma neta, mas embora elas todas me lembrassem minha avó materna, talvez por falta de costume, nunca consegui chamá-las de "vós", mas sim de "tias". D. Iracema, a mais idosa das quatro, e última falante monolíngue de Sakurabiat que eu conheci, faleceu em 2006. D. Mercedes Guaratira nos deixou em 2012. D. Vicência Sakyrabiar me contou essa e muitas outras histórias e, junto com as outras anciãs, me ensinou muito sobre sua língua, me acolheu e me ensinou também sobre a vida. Infelizmente, a voz de D. Vicência silenciou este ano, depois de muitas dores físicas e emocionais, ela faleceu neste mês de maio de 2020. D. Luzia Taapiroyat Sakyrabiar está viva, porém bastante debilitada pela idade e também pelo peso da dor de ter perdido um filho de forma violenta, já quase não fala nem escuta. Essas quatro mulheres, matriarcas do povo Sakurabiat foram vozes de resistência, desde os primeiros contatos com não indígenas, quando seu povo foi levado a trabalhar nos seringais e proibido de falar sua língua originária, até os anos recentes, quando enfrentaram epidemias de doenças contra as quais não tinham como lutar e perderam muitos parentes, enfrentaram invasões de suas terras por madeireiros e, nessa luta para a 
qual também não estavam preparadas, perderam alguns de seus filhos mais aguerridos. Elas também foram as guardiãs de sua língua originária, a língua que aprenderam com seus avós, assim como as histórias da poética de seu povo. Foram elas que garantiram a transmissão da língua até quando não puderam mais e a língua deixou de ser aprendida pelas novas gerações.

Nessa breve introdução, relato vários tipos de silenciamento, nenhum deles desejado. Neste momento, em que a convite dos editores deste volume, somos chamados a refletir sobre as relações entre língua(gem), política, pandemia, educação, cultura e sociedade, gostaria de levantar alguns pontos para reflexão sobre os silenciamentos impostos aos povos originários, com respeito especificamente ao uso das suas respectivas línguas tradicionais. Silenciamentos estes que se acentuam no contexto da pandemia por COVID-19 e da ausência de políticas públicas e ações apropriadas para conter o avanço dos problemas causados por essa crise de saúde.

O efeito do COVID-19 sobre os povos originários tem sido muito devastador. Segundo dados da APIB - Articulação dos povos indígenas do Brasil, até o presente momento, há informações de que já são 158 povos originários afetados por COVID-19 no Brasil, sendo que mais de 30 mil indígenas testaram positivo para a doença e mais de 800 morreram (APIB, 2020a) ${ }^{2}$. São muitas as perdas de crianças, jovens e idosos, de grandes lideranças, de grandes mestres de uma ciência que ainda desconhecemos, em sua quase totalidade, muitos deles falantes, em alguns casos, os últimos falantes de suas línguas tradicionais. Uma das metáforas mais bonitas e ao mesmo tempo mais tristes frequentemente usada nestes meses é a de que "bibliotecas inteiras estão sendo queimadas todos os dias" a cada morte de uma dessas pessoas, guardiãs de um conhecimento ímpar. São avós, são pais, são filhos, irmãos e irmãs, maridos e esposas, tios e tias, cunhados e cunhadas, amigos e amigas, são pessoas que têm muito a oferecer para os seus respectivos povos e para toda a humanidade. São especialmente vozes de resistência, guardiãs do conhecimento tradicional e das línguas tradicionais de seus povos.

Sabe-se que entre 6000 a 7000 línguas são faladas atualmente no mundo. Essa riqueza e enorme diversidade linguística também é observada no Brasil, que ao contrário da informação comumente divulgada, é um país multilíngue e um dos países com alta

\footnotetext{
${ }^{2}$ Esses dados estão sendo constantemente atualizados e podem ser consultados no endereço eletrônico: <http://emergenciaindigena.apib.info/dados_covid19/>. Acesso em: 17 ago. 2020.
} 
diversidade linguística no mundo. Além do português brasileiro e suas diversas variedades regionais, o país abriga línguas de imigração, falares afrodescendentes, línguas de sinais e as línguas dos povos originários. Estas últimas constituem a grande maioria das línguas faladas no país.

A contagem das línguas originárias no Brasil é uma tarefa complexa, considerando que muitas vezes há confusão entre nomes de línguas, dialetos, grupos e subgrupos, e que assim como ocorreu no passado, ainda ocorre atualmente a criação de nomes de línguas ou variedades sem a utilização de critérios explícitos para reconhecer variações como dialetos da mesma língua ou sem ter informações seguras sobre o grau de inteligibilidade mútua das línguas ou dialetos em questão. Moore, Galucio e Gabas Júnior (2008) estimam que as línguas originárias no país somam 154, sendo que sete são línguas isoladas, ou seja, sem relação genética conhecida com outras línguas, e as demais 147 são classificadas em 15 famílias linguísticas. Somente na região Amazônica são faladas mais de 100 línguas, que correspondem a cerca de dois terços das línguas originárias ainda faladas no país. Além disso, existem grupos indígenas que vivem sem contato com outros grupos da sociedade nacional e podem falar outras línguas, ainda desconhecidas.

Essas línguas representam uma parcela importante do patrimônio linguísticocultural da humanidade, no entanto encontram-se seriamente ameaçadas, como resultado de um processo histórico de silenciamento que já dura aproximadamente seis séculos. Estimativas feitas com base em relatos de viajantes e outros dados históricos apontam que cerca de $80 \%$ da diversidade cultural, étnica e linguística nativa do Brasil foi perdida/silenciada desde a invasão europeia. No mesmo levantamento, realizado há 12 anos e citado anteriormente (MOORE; GALUCIO; GABAS JUNIOR, 2008), indica-se que $25 \%$ das línguas originárias possuíam no máximo 50 falantes; apenas $18 \%$ possuíam mais de 1000 falantes. Há diversos casos no Brasil, onde a transmissão da língua foi interrompida há pelo menos duas gerações, levando a um contexto atual em que as novas gerações não falam e nem compreendem a língua tradicional de sua etnia, apenas conhecem palavras e expressões coloquiais. Entretanto, a relação afetiva e identitária com a língua tradicional de seu povo é bastante presente, sendo ela considerada a sua língua de pertencimento étnico. Essa é a situação, por exemplo, dos povos Sakurabiat e Puruborá (GALUCIO, no prelo) e de outros povos originários de Rondônia (GALUCIO; MOORE; 
VOORT, 2018).

As línguas minoritárias (aqui incluídas as mais de 150 línguas dos povos originários, as línguas de imigração, as línguas de sinais, etc.) são historicamente silenciadas, entre outros motivos, pelo efeito da política de hegemonia da língua portuguesa no país, e das políticas de estado e demais ações que enfatizam essa hegemonia, como os meios de comunicação, o sistema educacional, as instituições religiosas etc.. No tocante, especificamente às línguas dos povos originários, em realidade, não somente as línguas têm historicamente sido silenciadas no Brasil desde a invasão europeia, mas também os povos falantes dessas línguas sofreram e continuam sofrendo diversas formas de ataques a seus modos de vida, aos seus territórios e às suas próprias existências.

A situação da vitalidade linguística dos povos originários não melhorou nos últimos anos, ao contrário, os números indicativos da situação de vitalidade/obsolescência linguística estão ainda mais graves e agora se tornam ainda mais alarmantes no contexto da pandemia decorrente do COVID-19, especialmente devido à incapacidade do estado brasileiro de oferecer atenção adequada à população do país e particularmente aos povos indígenas. A população indígena representa uma parcela da sociedade que tem sido não apenas negligenciada pelo atual governo do país, mas tem sido ativamente atacada, o que motivou a APIB, a ajuizar ação contra a União, junto ao Supremo Tribunal Federal, para pedir não apenas a retirada dos invasores de suas terras, mas também a implementação de medidas de proteção e combate a COVID-19 nas aldeias (APIB, 2020b).

Voltemos agora para a narrativa que abre este texto. Um relato mítico que retrata um ser fantástico, que reúne características do grande felino da Amazônia ainda mais poderoso por ser alado. A narrativa conta do ataque, mas também da união do povo para destruir esse ser e vingar a morte prematura do jovem rapaz. Escolhi contar a história de ameko pebo piro ou "a onça que tinha asas" porque ela remete ao momento difícil enfrentado pelos povos originários aqui no Brasil e em outros países da Amazônia e do mundo, em que os povos estão sendo atacados, não por um animal mítico de asas, mas pela inexistência de ações eficazes de enfrentamento de uma crise que se prolonga por séculos, mas que assume proporções alarmantes no contexto do COVID-19. Línguas inteiras correm o risco de serem permanentemente silenciadas e de desaparecem 
totalmente, se morrerem seus últimos 3, 10, 20, 50 falantes. Como vimos acima, 25\% das línguas dos povos originários possuem até 50 falantes. Esse é o caso dos Sakurabiat, cuja população total na Terra Indígena Rio Mequens, não chega a 100 pessoas, e destes, apenas 12 são falantes fluentes da língua originária do povo. A crise para as línguas dos povos originários acentuada pelo COVID-19 é, pois, de uma proporção imensurável. Situação que foi ilustrada de forma contundente pelo Professor José Bessa Freire, em uma palestra proferida na série Abralin ao Vivo - Linguistas Online, em 05 de julho deste ano. Freire (2020) afirmou com muita propriedade que, "se 500 índios Tuyuca morrerem, a língua Tuyuca deixa de ser falada no Brasil. Se 1000 índios Tuyuca morrerem, incluindo os 500 que moram na Colômbia, a língua Tuyuca desaparece do planeta”.

E por que isso deveria nos preocupar? E por que isso nos afetaria? Primeiro porque estamos falando da vida/morte de pessoas. Mas também porque se as pessoas morrem e com elas desaparecem suas línguas, desaparece também uma multitude de saberes das mais variadas naturezas. A cada língua silenciada, todos perdemos. Perdemos a possibilidade de conhecer saberes produzidos por cada comunidade de fala, perdemos a possibilidade de experienciar a poética, a música, as narrativas fantásticas e míticas, como a narrativa do ameko pebo piro "a onça que tinha asas" e tantas outras. Imaginar quantos desses saberes foram silenciados para sempre com a morte prematura dos mais de 800 indígenas nos últimos meses é, a um só tempo, triste e revoltante, especialmente se considerarmos que muitas dessas mortes poderiam ter sido evitadas. Enquanto estudiosos da linguagem, garantir mais espaço às vozes dos povos originários e suas línguas pode ser a nossa forma de contribuir na luta pela sua sobrevivência. A valorização e o conhecimento das línguas indígenas são importantes para que possamos conhecer sua beleza e riqueza, mas também suas histórias e os caminhos percorridos pelos povos que as falam. Se pensarmos que há uma correlação direta entre diversidade linguística e cultural e democracia, deveríamos lutar para que nenhuma língua seja silenciada e desapareça, seja por quebra na transmissão, seja pela morte de seus falantes. Ao contrário, todas devem ser respeitadas, protegidas, conhecidas, valorizadas e celebradas, como lembrado pelo padre Bartolemeu Meliá, citado pelo professor José Bessa Freire na mesma palestra referida anteriormente - "a história da América é a história de suas línguas, que temos de lamentar quando morrem, que temos de visitar e cuidar quando enfermas, que podemos celebrar 
com alegres cantos de vida quando são faladas". Celebremos, então, as línguas e os povos originários e cuidemos para que não sejam mais silenciadas e silenciados.

\section{AGRADECIMENTOS}

Gostaria de agradecer a todos os falantes das línguas originárias do país pelo exemplo de luta e resistência, em particular ao povo Sakurabiat. Minha pesquisa com línguas originárias é apoiada pela Bolsa de Produtividade CNPQ - Processo 305843/2019-2.

\section{REFERÊNCIAS}

APIB. Panorama Geral da COVID-19. 2020a. Disponível em: <http://emergenciaindigena.apib.info/dados_covid19/>. Acesso em: 17 ago. 2020.

APIB. Vitória da APIB e dos povos indígenas no STF. 05 de agosto de 2020b. Disponível em: <http://apib.info/2020/08/05/vitoria-da-apib-e-dos-povos-indigenas-no-stf/>. Acesso em: 17 ago. 2020.

FREIRE, J. B. Línguas indígenas, línguas ameaçadas. Evento Abralin ao vivo: linguists online. Participação de Norma Almeida como mediadora. 05 jul. 2020. 1 vídeo (1h44min). Disponível em: <https://aovivo.abralin.org/lives/jose-r-bessa-freire/>. Acesso em: 18 ago. 2020.

GALUCIO, A. V. Línguas de herança, obsolescência linguística e motivações para aprendizagem no contexto da educação escolar indígena: reflexões, dúvidas e desafios. Cadernos de Linguística, v.2, n.1, no prelo.

GALUCIO, A. V.; MOORE, D.; VOORT, H. V. D. O patrimônio linguístico do Brasil: novas perspectivas e abordagens no planejamento e gestão de uma política da diversidade linguística. Revista do Patrimônio Histórico e Artístico Nacional, v.38, p.195-221, 2018.

MOORE, D.; GALUCIO, A. V; GABAS JUNIOR, N. O desafio de documentar e preservar as línguas amazônicas. Scientific American Brasil - Amazônia (A Floresta e o Futuro), Brasil, v.1, set., p.36-43, 2008. 